\title{
RHYTHM VARIABLES AS \\ TAXONOMIC CHARACTERS IN ANTS
}

\author{
By Elwood S. McCluskey ${ }^{1}$ And Siu-Ming A. Soong ${ }^{2}$ \\ Loma Linda University, Loma Linda, Ca 92350
}

A survey of many species of ants in the field indicates a generic difference in the hours of flight and of worker aboveground activity (McCluskey 1973, 1974). Further, species within the same genus may differ consistently (Holldobler 1976; Lévieux 1977; Whitford and Ettershank 1975). Would the same be true if the habitats of the various species were made identical? The present paper reports a beginning laboratory test of this question in worker ants. Secondly, it uses multivariate analysis to examine rhythm and other laboratory-type variables for their potential as taxonomic characters. A preliminary report was given by McCluskey and Soong (1978).

\section{METHODS AND MATERIALS}

The species observed were: Pogonomyrmex californicus (Buckley), Pogonomyrmex rugosus Emery, Veromessor andrei (Mayr), and Veromessor pergandei (Mayr) in the tribe Myrmicini of Myrmicinae; and Formica pilicornis Emery and Myrmecocystus mimicus Wheeler in the tribe Formicini of Formicinae. The ants were all collected May 24 and 25, 1973, near Loma Linda or Colton, San Bernardino County, California, at an elevation of about $350 \mathrm{~m}$.

Each group of ants was placed in a clear plastic refrigerator dish 9 $\mathrm{cm}$ in diameter by $3 \mathrm{~cm}$ deep. Sugar water was provided by a cottonplugged tube hanging down through the lid, and constant moisture by a wick of dental cotton projecting up from water in a like dish nested underneath. A clear plastic (Tygon) tube $8 \mathrm{~cm}$ long led to a dish of the same type to serve as a dry arena. The nest dish was totally covered by heavy black paper, while the tube and arena were fully exposed to the light.

\footnotetext{
'Departments of Biology and Physiology; address for reprints.

2Department of Biology; present address, 550 Victoria Road, Baguio Villa, Block 46, $3 \mathrm{~F}$, Hong Kong.

Manuscript received by the editor July 5, 1979.
} 
There were five of these nest assemblies per species (except only one for M. mimicus), with 30 ants in each. The 26 arenas were lined up side by side, the first replicate of each species, then the second of each, etc. Heating tape was stretched alongside the whole row of arenas so that it was about $1 \mathrm{~cm}$ from one side of each arena; it provided constant heat throughout the experiment.

The ants were kept in a constant temperature room. The nest dishes averaged $24.3^{\circ} \mathrm{C} \pm 0.5^{\circ}$. The hot side of the arenas was kept at least $10^{\circ}\left( \pm 1^{\circ}\right)$ hotter than this. Twelve hours of fluorescent light (2000 lux) was alternated with 12 hours of darkness (the last 2 nights there was dim incandescent light [15 lux] to permit observations).

The ants were installed May 25 and observations began May 27. Each hour during the light periods of May 27-31, and also during the 2 nights beginning May 30 and 31, the number in the hot half of the arena, in the warm half of the arena, and in the tube were counted visually. In addition, the total number active (moving) in tube and arena were counted.

Except where noted, an arc sine transformation was used, treating the count as a proportion of the 30 ants available (Dixon and Massey 1969). Then the transformed counts for the 3 days May 27-29, when the ants were in the best condition, were averaged for each replicate. Finally the hourly observations were fitted to a 24 -hour cosine-curve for determination of the best-fit peak (acrophase) and other rhythm parameters.

Variables evaluated

The fitting method used (Halberg et al. 1972) provides the acrophase, the level (average), the amplitude, and the sinusoidality (probability of sine shape) of the fitted rhythm. Each of these four parameters (dependent variables) could serve as a potential character, and each was applied to every one of the following four types of assay (Table 1).

Listed first are the variables related to the total number of ants out (i.e., in tube and arena) at each hour (TOTAL OUT). This would represent choice of an area exposed to alternating light and dark, as well as drier and warmer than the dark humid next dish.

The second type of assay was the number of ants in the hot half of the arena (TEMPERATURE). This represents the extreme distance out from the nest dish, and/or the preference or tolerance of high temperature. 
The third, POSITION, was calculated as $(.80 \times$ total no. out - no. in tube)/(total no. out - no. in hot half of arena). It is an index of how far out into the warm (i.e., nearest) half of the arena one would have to go to encompass $80 \%$ of the ants which were out of the nest at the time $(50 \%$ would not work, because too often the $50 \%$ line was down in the tube rather than out in the arena). This position assay may be illustrated by sample calculations: If all the ants were in the warm half of the arena, the $80 \%$ point would be $80 \%$ of the way out through the warm half. If $20 \%$ were in the warm half and $80 \%$ in the tube, the $80 \%$ point would be $0 \%$ of the way through the warm half. If $80 \%$ were in the warm half and $20 \%$ in the hot half, the $80 \%$ point would be $100 \%$ of the way out through the warm half.

The fourth, ACTIVITY, was the proportion active of the total number out.

The fitting involved above should increase the information content in any given variable. How important is this for taxonomic discrimination? To help answer the question, single "hourly" (i.e., nonfitted) variables were also tested (Table 1), each being simply the value for a particular hour.

Table 1. (see following pages)

Means of variables examined for taxonomic value, averaged over days (May 27-29 except where noted) and replicate nests for each species (abbreviated by initial of genus and species). TOTAL OUT and TEMPERATURE based on arc sine transformation of count; POSITION based on raw count; ACTIVITY based on log of proportion active. Sinusoidality represented by $\log$ of $\mathrm{F}$ statistic, Acrophase by clock hour (decimal form: e.g., 15.8 = 3:48 PM; angular avg), and Level and Amplitude by number of ants (except for POSITION, where Level and Amplitude represent distance into arena-see text); these first 4 variables under each type of assay are all derived by least-squares cosine-fitting (Halberg et al., 1972). The next 6 variables under TOTAL OUT are: Shift of Acrophase (no. of h change in acrophase from May 27 to May 29); Rise (h at which count passed up through avg [Level] for the day); Shift of Rise (no. of h change from May 27 to May 29); Above Average (no. of h above avg for the day, May 30-31, when observed all 24 h); Light-on Difference (between count immediately after lights on and 2d count several min later, May 28-30); Fluctuation (no. of runs, where "run" = series of hourly values each having same sign of change from preceding value). Corresponding to latter is Fluctuation under Position. Finally, under each type are listed the hourly values, unprocessed except for initial transformation and averaging (ACTIVITY 0700 omitted because could not observe all replicates simultaneously at the moment lights came on). F based on 5,20 degrees of freedom (slightly less for some variables with missing observations); $*=\mathrm{P}<.05, * *$ $=<.01, * * *=<.001$. 
TABle 1

\begin{tabular}{|c|c|c|c|c|c|c|c|}
\hline \multirow[t]{2}{*}{ Variable } & \multicolumn{6}{|c|}{ Species } & \multirow[t]{3}{*}{$\underline{F}$} \\
\hline & P.C. & P.r. & V.a. & V.p. & F.p. & M.m. & \\
\hline \multicolumn{7}{|l|}{ TOTAL OUT } & \\
\hline Sinusoidality & 1.79 & 1.81 & 1.74 & 1.62 & 1.45 & 1.83 & .9 \\
\hline Level & 72 & 83 & 83 & 45 & 65 & 56 & $4.8^{* *}$ \\
\hline Amplitude & 25 & 32 & 41 & 28 & 23 & 19 & 1.5 \\
\hline Acrophase & 15.8 & 18.0 & .7 & 22.5 & 23.4 & 20.8 & $23.3^{* * *}$ \\
\hline Shift of acro. & 1.4 & 4.0 & .9 & .3 & 2.1 & 2.8 & 2.4 \\
\hline Rise & 10.7 & 11.9 & 18.4 & 16.0 & 17.1 & 14.6 & $15.1 * \star *$ \\
\hline Shift of rise & 1.3 & 3.9 & .6 & -1.0 & 1.3 & 2.2 & $4.0 * \star$ \\
\hline Above average & 15.0 & 12.6 & 12.7 & 9.2 & 11.4 & 13.0 & $6.4 * \star$ \\
\hline Light-on diff. & 28.2 & 40.2 & 40.8 & 6.2 & 41.6 & 10.5 & $4.2 \star \star$ \\
\hline Fluctuation & 16.2 & 15.4 & 13.0 & 10.8 & 18.2 & 16.0 & $4.3^{\star \star}$ \\
\hline 0700 & 59 & 62 & 85 & 25 & 60 & 41 & $5.6^{\star \star}$ \\
\hline 0800 & 60 & 55 & 61 & 22 & 47 & 34 & 2.7 \\
\hline 0900 & 64 & 61 & 55 & 20 & 44 & 30 & $2.9 *$ \\
\hline 1000 & 70 & 65 & 49 & 20 & 45 & 45 & $2.9 *$ \\
\hline 1100 & 74 & 74 & 48 & 21 & 44 & 41 & $4.2^{\star \star}$ \\
\hline 1200 & 81 & 84 & 48 & 21 & 43 & 42 & $6.4^{\star \star}$ \\
\hline 1300 & 89 & 91 & 47 & 23 & 44 & 41 & $8.7 * \star \star$ \\
\hline 1400 & 92 & 99 & 45 & 24 & 46 & 50 & $11.8^{* * *}$ \\
\hline 1500 & 96 & 106 & 49 & 31 & 52 & 59 & $15.0 * \star *$ \\
\hline 1600 & 97 & 110 & 57 & 45 & 58 & 66 & $11.8 * \star \star$ \\
\hline 1700 & 95 & 109 & 67 & 55 & 65 & 66 & $5.5^{\star \star}$ \\
\hline 1800 & 93 & 111 & 79 & 57 & 70 & 69 & $7.0 * \star *$ \\
\hline 1900 & 86 & 110 & 88 & 61 & 72 & 72 & $4.5^{\star \star}$ \\
\hline \multicolumn{8}{|l|}{ POSITION } \\
\hline Sinusoidality & 1.78 & .92 & .79 & 1.18 & .44 & .18 & $9.3^{* * *}$ \\
\hline Level & 89 & 69 & 70 & 30 & 3 & 59 & $9.8^{* \star *}$ \\
\hline Amplitude & 42 & 12 & 13 & 13 & 14 & 9 & $3.9 *$ \\
\hline Acrophase & 20.6 & 18.7 & 3.4 & 11.0 & 14.5 & 20.1 & $5.2 \star \star$ \\
\hline Fluctuation & 19.6 & 20.6 & 17.7 & 11.0 & 23.7 & 22.0 & $6.3^{* \star}$ \\
\hline 0700 & 57 & 48 & 74 & 45 & 1 & 2 & $5.4^{\star \star}$ \\
\hline 0800 & 46 & 60 & 78 & 47 & 0 & 87 & $3.4 *$ \\
\hline 0900 & 52 & 62 & 81 & 31 & 1 & 73 & $3.8^{*}$ \\
\hline 1000 & 47 & 66 & 60 & 31 & 8 & 41 & 1.8 \\
\hline 1100 & 49 & 63 & 62 & 43 & 14 & 64 & 1.2 \\
\hline 1200 & 61 & 70 & 61 & 43 & 9 & 49 & 2.2 \\
\hline 1300 & 66 & 67 & 58 & 44 & 19 & 54 & 1.4 \\
\hline 1400 & 77 & 73 & 61 & 46 & 19 & 62 & 2.1 \\
\hline
\end{tabular}


TABLE 1 (CONTINUED)

\begin{tabular}{|c|c|c|c|c|c|c|c|}
\hline 1500 & 109 & 70 & 56 & 40 & 19 & 45 & $4.5^{\star *}$ \\
\hline 1600 & 110 & 77 & 55 & 36 & 14 & 60 & $7.8 * * *$ \\
\hline 1700 & 118 & 78 & 62 & 28 & 18 & 68 & $20.7 \star \star \star *$ \\
\hline 1800 & 116 & 84 & 56 & 24 & 6 & 55 & $12.5 * \star \star$ \\
\hline 1900 & 121 & 83 & 62 & 21 & 9 & 90 & $14.3 * \star \star$ \\
\hline \multicolumn{8}{|l|}{ TEMPERATURE } \\
\hline Sinusoidality & 1.72 & 1.36 & .58 & .29 & .24 & 1.00 & $11.9 * \star \star$ \\
\hline Level & 31.7 & 24.5 & 14.0 & 11.5 & 11.7 & 19.7 & $5.6 \star \star$ \\
\hline Amplitude & 20.8 & 14.0 & 4.1 & 1.0 & .8 & 9.6 & $6.9 * \star \star$ \\
\hline Acrophase & 19.2 & 21.8 & 1.4 & 1.8 & .5 & 23.1 & 2.1 \\
\hline 0700 & 14 & 13 & 18 & 13 & 12 & 10 & .8 \\
\hline 0800 & 12 & 12 & 12 & 12 & 12 & 15 & .4 \\
\hline 0900 & 14 & 12 & 11 & 10 & 10 & 13 & $3.5^{\star}$ \\
\hline 1000 & 14 & 12 & 10 & 10 & 11 & 10 & $3.2^{\star}$ \\
\hline 1100 & 17 & 11 & 10 & 10 & 11 & 13 & $10.8 * \star \star$ \\
\hline 1200 & 23 & 11 & 10 & 10 & 11 & 10 & $20.9 \star \star \star$ \\
\hline 1300 & 30 & 15 & 11 & 10 & 11 & 10 & $13.5^{* * *}$ \\
\hline 1400 & 33 & 17 & 11 & 11 & 11 & 10 & $6.3^{\star \star}$ \\
\hline 1500 & 49 & 22 & 10 & 12 & 10 & 13 & $13.2 * \star \star$ \\
\hline 1600 & 49 & 25 & 11 & 10 & 11 & 20 & $14.5 * \star \star$ \\
\hline 1700 & 52 & 29 & 13 & 12 & 13 & 20 & $10.3^{\star \star \star}$ \\
\hline 1800 & 51 & 32 & 12 & 11 & 12 & 15 & $9.0 * \star \star$ \\
\hline 1900 & 47 & 35 & 12 & 10 & 11 & 31 & $7.4 * \star \star$ \\
\hline \multicolumn{8}{|l|}{ ACTIVITY } \\
\hline Sinusoidality & .75 & .78 & .55 & .84 & .63 & .11 & 1.3 \\
\hline Level & .91 & 1.09 & .93 & .53 & .94 & .60 & $4.0 * \star$ \\
\hline Amplitude & .24 & .33 & .65 & .39 & .37 & .18 & $3.0 *$ \\
\hline Acrophase & 20.6 & 19.7 & .4 & 22.4 & .0 & 12.5 & $3.4^{*}$ \\
\hline 0800 & 77 & 82 & 90 & 49 & 61 & 42 & .8 \\
\hline 0900 & 71 & 91 & 58 & 18 & 59 & 114 & $2.8^{\star}$ \\
\hline 1000 & 58 & 68 & 26 & 8 & 62 & 79 & $3.1^{*}$ \\
\hline 1100 & 55 & 84 & 6 & 0 & 75 & 39 & $10.7 * \star \star$ \\
\hline 1200 & 88 & 90 & 18 & 0 & 54 & 82 & $9.2 * \star *$ \\
\hline 1300 & 83 & 103 & 29 & 12 & 69 & 84 & $7.6^{\star \star \star}$ \\
\hline 1400 & 67 & 111 & 14 & 23 & 50 & 81 & $4.9 * \star$ \\
\hline 1500 & 103 & 124 & 44 & 43 & 84 & 69 & $4.3^{\star \star}$ \\
\hline 1600 & 103 & 138 & 103 & 64 & 83 & 85 & $3.5^{\star}$ \\
\hline 1700 & 106 & 142 & 106 & 73 & 92 & 73 & $5.5^{\star \star}$ \\
\hline 1800 & 103 & 134 & 67 & 50 & 113 & 23 & $8.0^{\star \star \star}$ \\
\hline 1900 & 107 & 133 & 73 & 49 & 117 & 80 & $6.2^{\star \star}$ \\
\hline
\end{tabular}


Several miscellaneous variables are also shown in Table 1 , such as "shift of acrophase." They and the fitted variables will be referred to as "processed" variables to distinguish them from the "hourly" ones.

Multivariate analysis of variance (MANOVA) and multidiscriminant analysis were used for comparison of species by groups of variables. These methods apply even where variables are highly correlated, which many of those here certainly are. On the basis of known group membership, discriminant analysis emphasizes variables that have a high ratio of among-group to within-group variation. Thus the variables are weighted so as to discriminate optimally between the groups (here species). An introduction to these methods is given by Cooley and Lohnes (1971), and application to behavioral research, by Pimentel and Frey (1978).

\section{RESULTS}

\section{Daytime observations}

For both species of Pogonomyrmex the total number out rose in early midday and remained high through the afternoon (Figure 1). For the other species the number rose in the afternoon and continued rising through the end of the light period.

In $V$. pergandei and $F$. pilicornis few ants ever came out as far as the arena; the rhythmic count was made up largely of those in the tube leading to the arena (Figure 1). In $V$. andrei the proportion in the tube was relatively high at the first and last of the light period. The proportion reaching the hot side of the arena was the greatest in $P$. californicus.

For most of the analyses, only these daytime observations were used.

\section{4-hour observations}

After 3 days very dim lights were left on at night, permitting counts then. It was now 6 days after collection from the field, and some of the ants were dead or else came out into the tubes or arenas less frequently. Nevertheless the patterns for the "day" part of the cycle were similar to before. And now it could be seen that all six species were prominently out in the arenas during the night.

That this nocturnal behavior might be explained by the constant high temperature is suggested by field observations. Tevis (1958) found that nocturnal foraging of $V$. pergande $i$ is rare, but could occur if temperatures are higher than normal; Wheeler and Rissing 


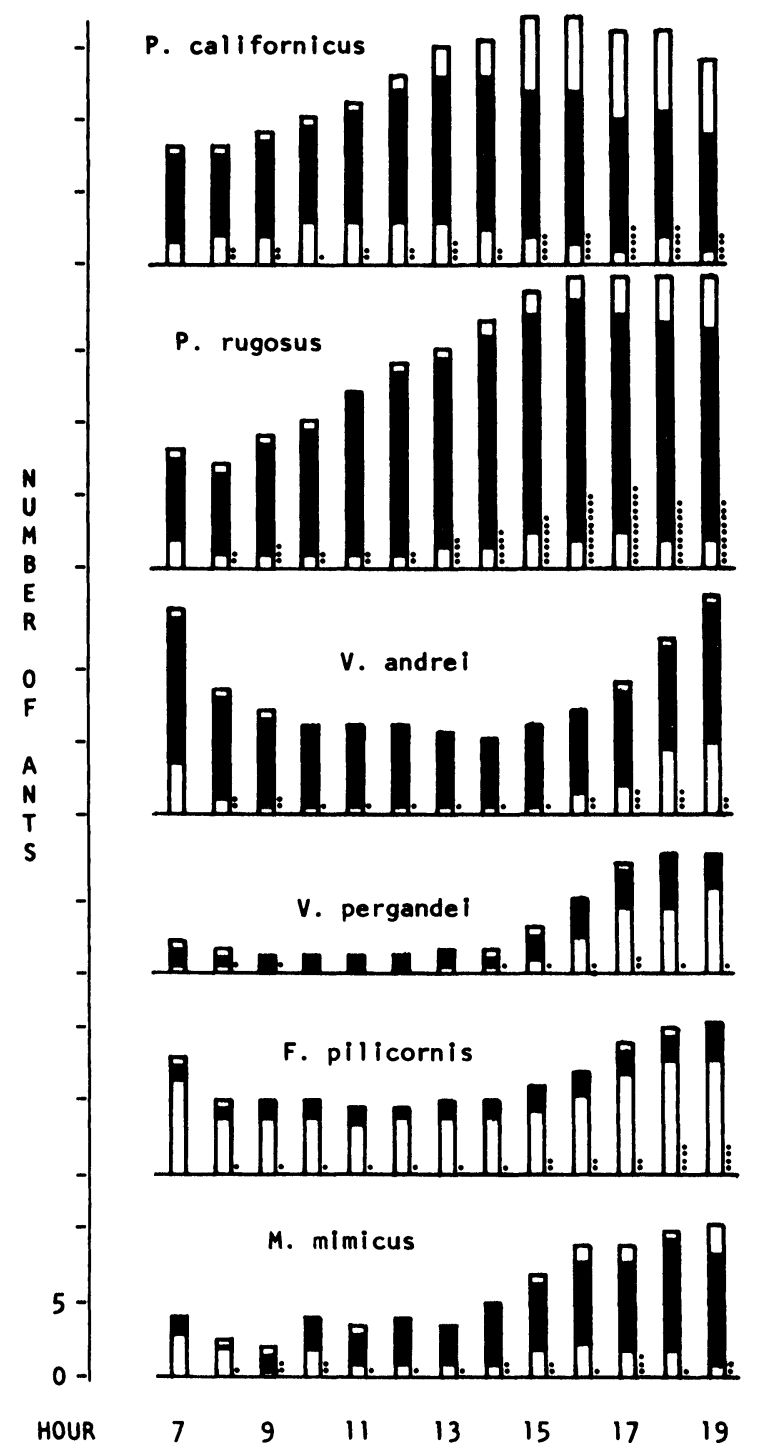

Figure 1. Comparative time patterns during light part of light-dark cycles. Histograms based on raw counts averaged over the 3 days (May 27-29) and 5 replicate nests ( 1 nest for $M$. mimicus) for each species. Each bar represents total number of ants out at a given observation: bottom part, tube count; middle (shaded), warm half of arena; top, hot half of arena. Dotted line to right of bar represents number active of total number out (omitted for 0700). 
(1975) found it to be common in the summer. McCluskey (1963) reported foraging in V. andrei on warm nights. P. californicus sometimes works at night (Cole 1932), and P. rugosus does so when warm (Whitford and Ettershank 1975).

\section{Evaluation of variables as taxonomic characters}

By virtue of the replicates it was possible to test each variable for species difference by one way analysis of variance, or in the case of phase variables, by the circular distribution test of Watson and Williams (1956) (Table 1). The differences are significant for 42 of the 51 hourly and 18 of the 23 processed variables, suggesting value as species characters. The hourly variables for the last third of the day are more discriminating than those earlier.

Thus most of the individual variables distinguish species at least in a general way. As a group would they distinguish between the members of each pair of species? Multidiscriminant analysis was used to answer this (somewhat as Brown and Shipp, 1977, did to evaluate wing morphometric characters).

M. mimicus, with only one replicate, was omitted. MANOVA indicates a significant $(P<.01)$ difference among the other five species, whether based on processed or on hourly variables. Therefore it is appropriate to use multidiscriminant analysis for further examination of the differences. For the set of processed variables, Figure 2 shows the maximum discrimination possible in twodimensional space. The replicates are well segregated into their respective species. The same was true if based on either of the two stratified subsets of 17 hourly variables tried (not shown). Further analysis is not attempted here because of small sample size.

The method was checked by deliberately assigning half the replicates initially to incorrect species. The variables then failed to segregate the replicates well into the artificial species, or even to show a significant species difference by MANOVA.

\section{Later experiment}

As laboratory projects in a comparative physiology course, the same species of Pogonomyrmex and Veromessor were compared simultaneously as before, but the conditions were different. Most notably, the season was October instead of May; and the temperature was cycled between $20^{\circ} \mathrm{C}$ at night and $30^{\circ}\left(35^{\circ}\right.$ in hottest part of arena) at midday, instead of being held constant. 


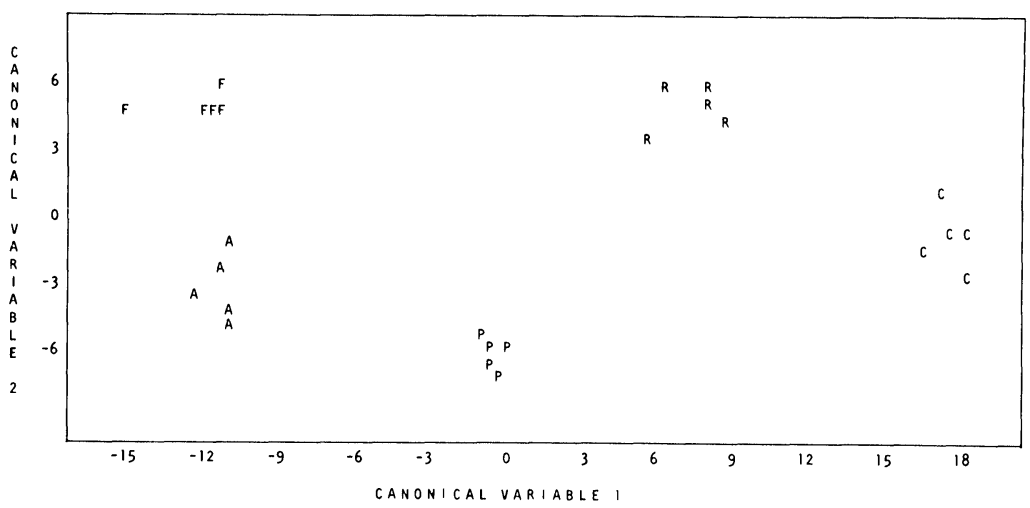

Figure 2. The first two canonical axes, based on all 17 processed variables for which every one of the 25 cases ( 5 species $\times 5$ replicates) was represented, and for which (phase variables) distribution was across few enough hours to assume linearity. The first axis represents the greatest possible difference between species, and the second, the greatest remaining difference orthogonal to the first. Output from the BMDP7M program, run so as to bypass the stepwise feature (as recommended by Pimentel and Frey, 1978). $\mathrm{A}=V$. andrei; $\mathrm{C}=P$. californicus; $\mathrm{F}=F$. pilicornis; $\mathrm{P}=$ $V$. pergande $; \mathrm{R}=P$. rugosus.

The results again suggest taxonomic differences in rhythm. The cosine-fitted acrophases of number out differed $(\mathrm{P}<.01)$ among the four species.

\section{DISCUSSION}

The study conditions were highly artificial-colony fragments (workers only, and in small number), no soil in the nest, temperature high all 24 hours, etc. The fact that the rhythms were nevertheless striking indicates that at least some of the natural field conditions (e.g., temperature cycle) are not necessary for such behavior.

But the important thing was that the six species were now all under the same conditions. Evidently various species manifest different patterns of rhythm even though in identical habitat; or to put it another way, it is not necessarily differences in field habitat that are responsible for the differences in rhythm. For a laboratory example of phase or pattern difference in another insect group, see Hardeland and Stang's (1973) comparison of 40 species of Drosophila. 
Many location and activity variables were tested in the six species for their potential as taxonomic characters, including cosine-fitted rhythm parameters as well as simple hourly values (Table 1). For most of them the species difference was significant.

By contrast with the fitted-rhythm and other processed variables, the hourly variables taken singly can indicate only the level (of activity or location) at a given hour. In the aggregate they become more meaningful. For example, scanning the hourly $\mathbf{P}$ values in Table 1 indicates one time of day to be more important than another in distinguishing species. Or more formally, a multivariate approach can compare in terms of the whole hourly pattern. MANOVA confirmed the overall species difference, and multidiscriminant analysis made it possible to discriminate each species from the others. It should be noted again that the purpose here is to examine these variables as taxonomic characters, rather than to develop a classification.

Nearly every one of the processed variables was abstracted from all the hourly values of a given type of assay, and hence should have high information content. So it is noteworthy that the groups of hourly variables seemed to distinguish species about as well as the group of processed ones. However, if some of both kinds were included in the same analysis, the most highly weighted were processed variables. most highly weighted were processed variables.

How might the list in Table 1 be compared with catalogues of ant behavior, such as that of Wilson (1976)? In the first place, the variables reported here were population rather than individual phenomena. Secondly, many of them are derived rhythm parameters (e.g., acrophase or amplitude) of certain items of behavior, rather than the behavior itself. The hourly variables, on the other hand, do represent behavior more directly (e.g., the number active or the number in the hot location, at a given point in time). Any comprehensiveness of catalogue (e.g., for choice of heat or light or location in the nest assembly) would require more habitat complexity, and preferably field studies as well. But such comprehensiveness is needed to facilitate behavioral comparisons at species or higher levels (Wilson 1976).

In summary, this study suggests a variety of rhythm-related characters that might be observed in laboratory or field, whether single hourly values, composite hour-by-hour patterns, or fitted rhythm parameters. 


\section{SUMMARY}

In the field the time of day of certain types of behavior distinguishes various species and genera. Would the same be true if their habitats were made identical? And could rhythm-related variables in general be regarded as taxonomic characters? Groups of workers of Pogonomyrmex californicus, $P$. rugosus, Veromessor andrei, $V$. pergandei, Formica pilicornis, and Myrmecocystus mimicus were studied simultaneously in constant temperature and alternating light and dark. A hot dry area and a dark humid area were available in each nest for choice at all hours. This permitted different types of position or activity assays and the calculation of several cosinefitted rhythm parameters for each. These as well as simple hourly values served as variables. For most of the variables tested there was a significant species difference. With multidiscriminant analysis it was possible to go beyond this general species difference and segregate the replicates of each species from those of other species; either the hourly or the more highly processed variables were adequate here. This study suggests a variety of rhythm-related characters that might be observed in laboratory or field.

\section{ACKNOWLEDGMENTS}

The data on which this report is based are largely from the second author's M.A. thesis research (Loma Linda University, 1975). We thank André Francoeur for determining $F$. pilicornis and Roy Snelling, M. mimicus; Glen McCluskey and Duane Zimmerman for programming; Paul Yahiku and Richard Pimentel for statistical help; and Leonard Brand, Conrad Clausen, David Kissinger, Gerald Scherba and Paul Yahiku for reading earlier drafts of the manuscript. Computer time was supported in part by NIH, Grant RR00276. Also used were BMDP programs developed at UCLA with NIH support.

\section{Literature Cited}

BRown, K. R., AND E. Shipp.

1977. Wing morphometrics of Australian Luciliini (Diptera: Calliphoridae). Aust. J. Zool. 25:765-777.

COLE, A. C.

1932. Notes on the ant Pogonomyrmex californicus, Buckley (Hym.: Formicidae). Entomol. News 43:113-115. 
Cooley, W. W., AND P. R. Lohnes.

1971. Multivariate data analysis. Wiley, New York.

Dixon, W. J., AND F. J. Massey, JR.

1969. Introduction to statistical analysis, 3d ed. McGraw-Hill, New York.

Halberg, F., E. A. Johnson, W. Nelson, W. Runge, and R. Sothern.

1972. Autorhythometry-procedures for physiologic self-measurements and their analysis. Physiology Teacher 1(4):1-11.

Hardeland, R., and G. STANG.

1973. Comparative studies on the circadian rhythms of locomotor activity of 40 Drosophila species. J. Interdisc. Cycle Research 4:353-359.

HOLLDOBLER, B.

1976. The behavioral ecology of mating in harvester ants (Hymenoptera: Formicidae: Pogonomyrmex). Behavioral Ecology and Sociobiology 1:405423.

LÉvieuX, J.

1977. La nutrition des fourmis tropicales: V.-Eléménts de synthèse. Les modes d'exploitation de la biocoenose. Insectes Soc. 24:235-260.

MCCluskey, E. S.

1963. Rhythms and clocks in harvester and Argentine ants. Physiol. Zool. 36:273-292.

1973. Generic diversity in phase of rhythm in formicine ants. Psyche 80:295304.

1974. Generic diversity in phase of rhythm in myrmicine ants. J. New York Entomol. Soc. 82:93-102.

McCluskey, E. S., AND S. A. Soong.

1978. Rhythm and other laboratory characters in a taxonomic comparison of ants. In Abstracts of papers of the 144th national meeting 12-17 February 1978 (ed. A. Herschman), p. 134. Amer. Assoc. Adv. Sci., Washington.

Pimentel, R. A., and D. F. Frey.

1978. Multivariate analysis of variance and discriminant analysis. Chapter 9 in Quantitative Ethology (P. W. Colgan, ed), Wiley, New York.

TEvis, L.

1958. Interrelations between the harvester ant Veromessor pergandei (Mayr) and some desert ephemerals. Ecology 39:695-704.

Watson, G. S., and E. J. Williams.

1956. On the construction of significance tests on the circle and the sphere. Biometrika 43:344-352.

WhEELER, J., AND S. W. RISSING.

1975. Natural history of Veromessor pergandei. II. Behavior. Pan-Pacific Entomologist 51:202-314.

Whitford, W. G., AND G. ETtershank.

1975. Factors affecting foraging activity in Chihuahuan desert harvester ants. Environmental Entomology 4:689-696.

WILSON, E. O.

1976. A social ethogram of the neotropical arboreal ant Zacryptocerus varians (Fr. Smith). Anim. Behav. 24:354-363. 

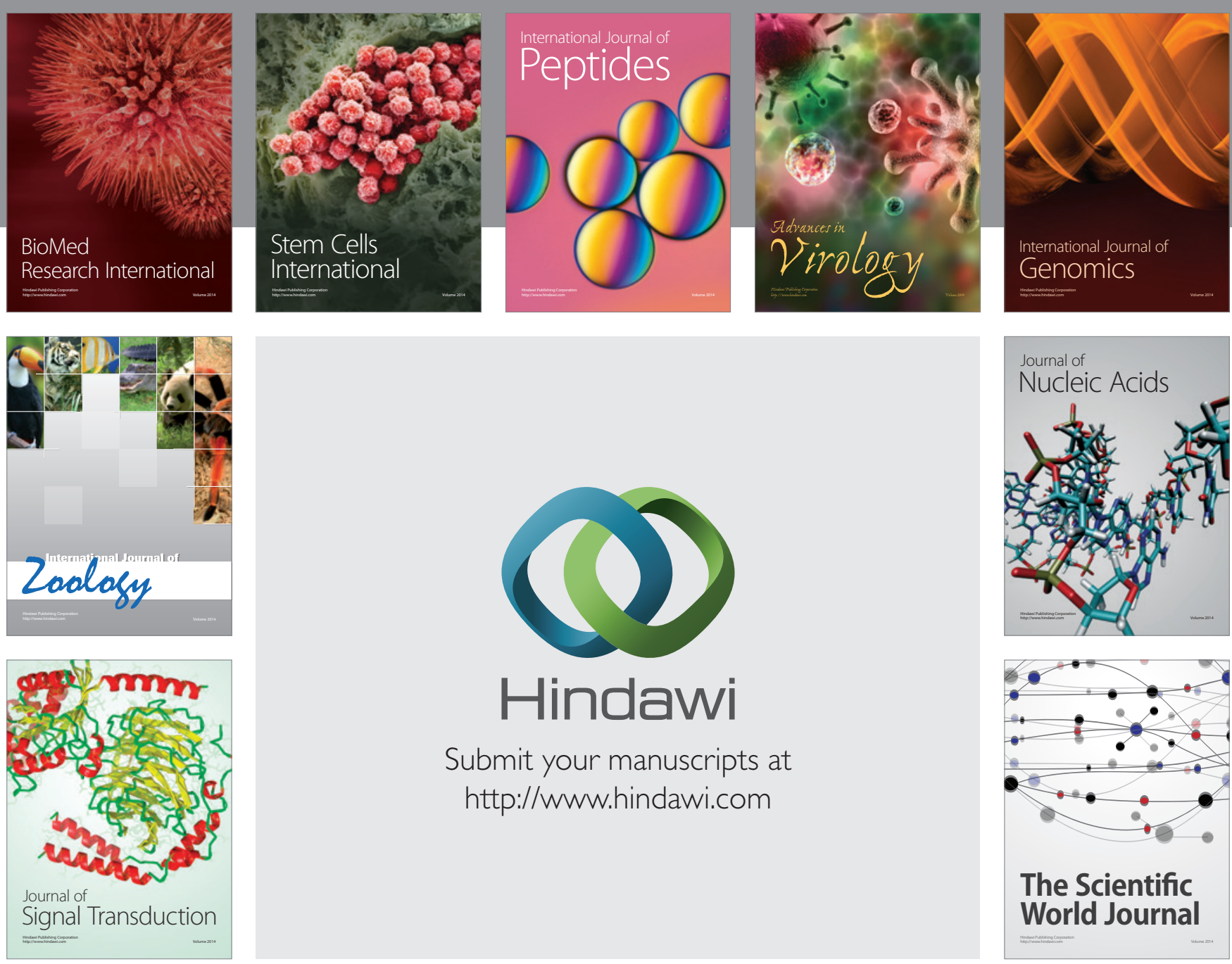

Submit your manuscripts at

http://www.hindawi.com
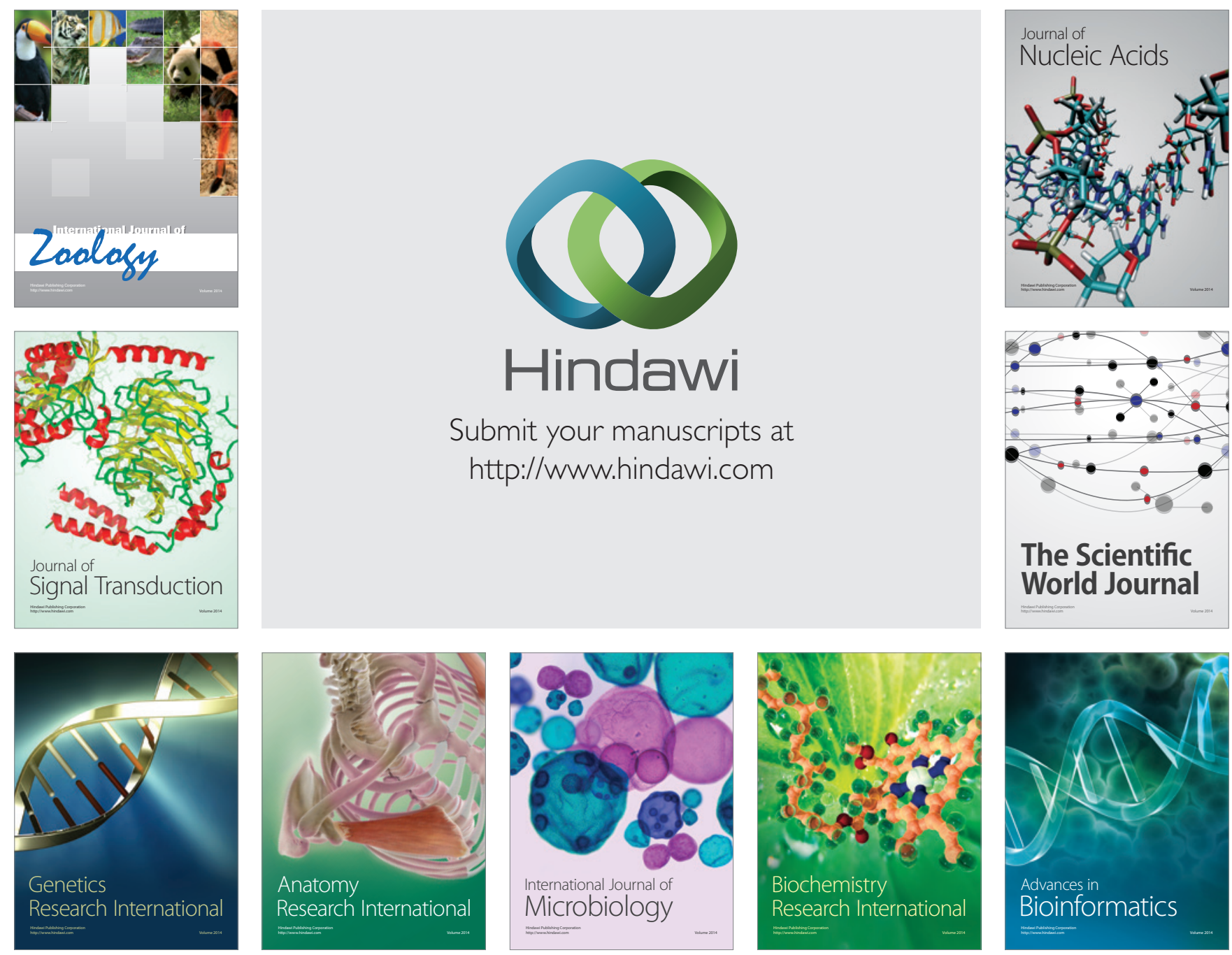

The Scientific World Journal
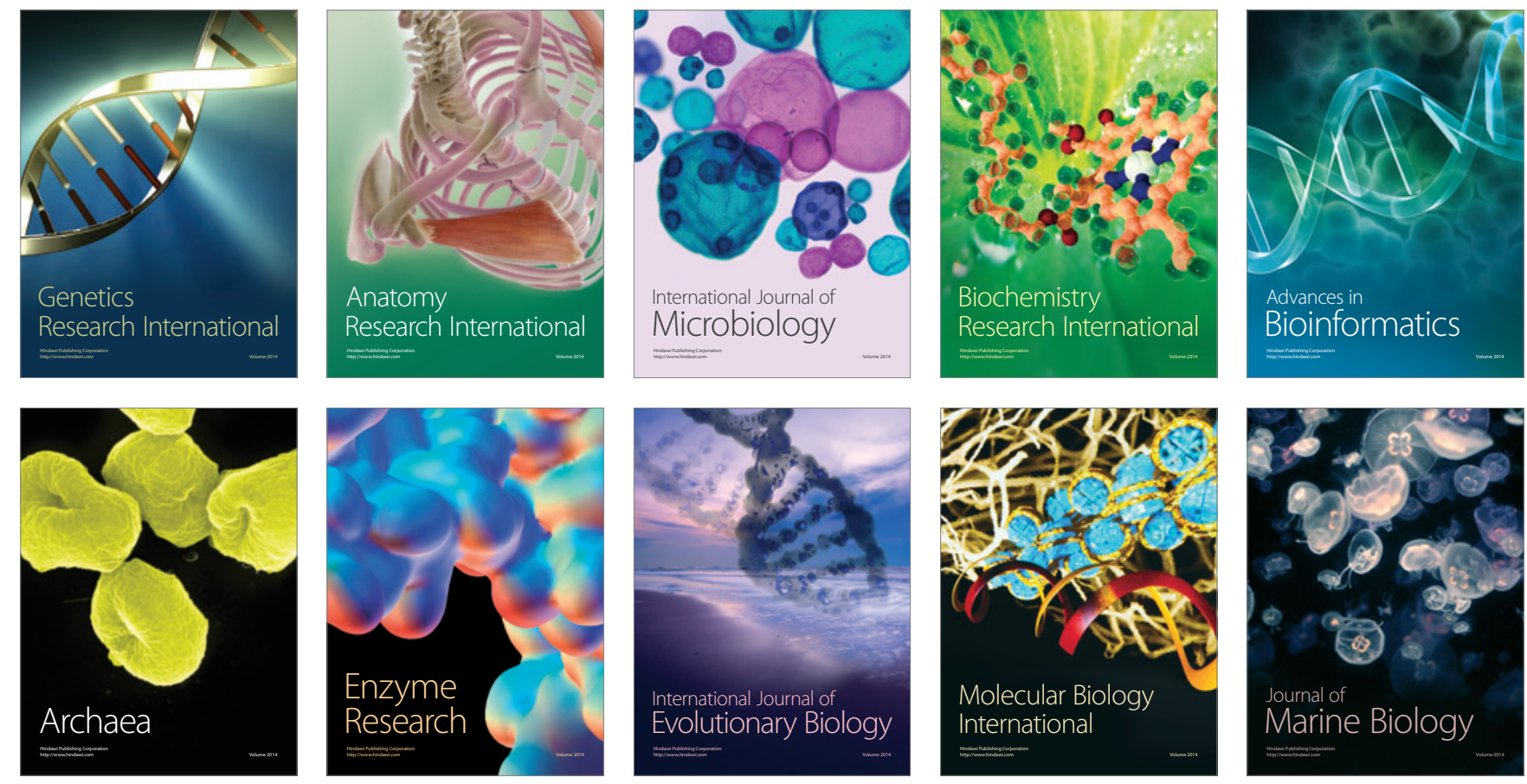